\title{
Modeling ovoproduct spoilage with red led light
}

\author{
E.C. Correa ${ }^{(1)}$, V. Diaz-Barcos and J. Fuentes- \\ Pila \\ Escuela Universitaria de Ingeniería Técnica \\ Agrícola \\ Universidad Politécnica de Madrid (Spain) \\ ${ }^{(1)}$ Physical Properties and Advanced Techniques \\ in Agrofood Laboratory. LPF-TAG
}

P. Barreiro ${ }^{(1)}$ and M.C.
González
Escuela Técnica Superior de
Ingenieros Agrónomos
Universidad Politécnica de
Madrid (Spain)

Keywords: Light Emitter Diodes, ovoproduct, spoilage, microorganisms, red light, pasteurization

\begin{abstract}
Heat-treatment of ovoproducts is often required to ensure microbial safety. However, it has been shown that in most microbial species slow heating, or heat shocks may induce a higher heat resistance, that means that it is not possible to remove the microbial flora completely. These microorganisms produce on ovoproducts spoilage especially when the cold chain is broken along the transportation and/or storage. As a result, the life span for the product is shortened. The microbial activity inside the product causes changes in several physical properties, which can be supervised using optical methods. The aim of this work is to monitor the sigmoid behaviour underlying the ovoproduct evolution and spoilage by means of red LED light. For two commercial types of liquid and pasteurized egg white, storage at $9^{\circ} \mathrm{C}$, an average correlation of $r=0.94$ has been found between microorganism growth and mean grey level of LED light passing though the sample. The results show that it is possible to develop very simple predictive models taking into account only one optical parameter corresponding to a single LED.
\end{abstract}

\section{INTRODUCTION}

Ovoproducts show very high sensitivity to microbiological spoilage which makes necessary to apply a thermal treatment to ensure its innocuity. Industrial pasteurisation of liquid egg (white, yolk and whole egg) typically consists of heating at temperatures between 57 and $72{ }^{\circ} \mathrm{C}$ for times ranging from a few seconds to about $10 \mathrm{~min}$, depending on the temperature, the product and the pasteurisation system. This treatment is designed to inactivate pathogenic microorganisms such as Salmonella without damaging the physico-chemical and functional properties of ovoproducts. However, such thermal treatment does not ensure complete eradication of the microbial flora (Guilmineau and Kulozik 2007). Slow heating, or heating for short periods of time at temperatures above the optimum for growth (heat shocks) may induce for most microbial species a higher heat resistance (Mañas et al. 2003), which leads to limited shelf life of the ovoproduct and the need for storing at $4{ }^{\circ} \mathrm{C}$ maximum (Guilmineau and Kulozik 2007).

Spanish producers recommend $2^{\circ} \mathrm{C}$ as optimal storage temperature for every step in the cold chain. One of the main consumers of ovoproduct, the catering trade industry, is not able to ensure such conditions due to frequent doors opening which leads to storage temperatures of 8 or $9^{\circ} \mathrm{C}$ in cold rooms. 
The reference method for addressing the microbiological load of one sample is the determination of the concentration of mesophilic microorganisms counting the amount of colonies forming units (CFU). A sigmoid function can be used as primary model to describe the growth curve of microorganisms (Cairé et al 2007). On the other hand, several studies show the effect of heat treatment and or microbiological spoilage on some properties of ovoproducts as turbidity, colour and viscosity (Hou et al. 1996) and gel properties (Coimbra et al. 2006). These physical properties can be supervised by means of optical techniques.

At present time there are some instruments that make use of light emitter diodes (LEDs) to the automatic supervision of coagulation processes as i.e. the cheese clotting process (Castillo et al 2006). The aim of this work is to address the sigmoid behaviour underlying the ovoproduct evolution and spoilage by means of red LED light.

\section{MATERIALS AND METHODS}

The study was carried out at summer time, critic season for preservation of perishable goods. Liquid egg white pasteurized ovoproduct was transported directly from the producing industries in refrigerate trucks and later it was stored in industrial refrigeration cameras at the School of Agricultural Technical Engineering of the UPM for its conservation at of $2^{\circ} \mathrm{C}$ (control) and $9^{\circ} \mathrm{C}$ temperatures. Two kinds of commercial products were used, the first one corresponds to Traditional Pasteurization to $57-58^{\circ} \mathrm{C}$ during 3 minutes (TP), while the second one refers to a High Temperature $60-62^{\circ} \mathrm{C}$, and Short Time 150s product (HTST) with aseptic packaging, which implies that the life span of HTST product is longer than TP product.

The optical test was carried out on three samples for ovoproduct with three repetitions for sample, at three or four times along the life span of ovoproduct depending on the storage temperature and product. For storage at $2^{\circ} \mathrm{C}$, TP was tested at 0,14 and 40 days and HTST at 0,21 and 63 days from reception. For storage at $9^{\circ} \mathrm{C}$, TP was tested at 0,6 and 9 days and HTST at 0, 5, 6 and 8 days. The samples were characterized by determination of their microbiological load by counting the $\mathrm{CFU} / \mathrm{ml}$ along the life span of each type of ovoproduct.

The optical system consisted of a black chamber where a transparent vat, filled with $1 \mathrm{~cm}$ deep of ovoproduct, is placed directly on top of the LEDs' array. A methacrylate's plate inlaid with eight LEDs mounted linearly was used to build that array, using red LED at $650 \mathrm{~nm}$ of wavelength. Fig. 1 shows how the detector used, a 3CCD IRRB camera (MS3100 Duncantech ${ }^{\circledR}$ ) with a sensibility window at $650 \mathrm{~nm}$ of $\pm 20 \mathrm{~nm}$, takes the image of red light passing through out the sample.

The images obtained were analysed using denoted Matlab programs. A treatment of raw image was implemented by image segmentation to convert an intensity image to a binary image. Each image was segmented twice: once by automatically generated segmentation threshold (Fig. 2, right) based on Otsu's method (Grey Level 1) which chooses the threshold to minimize the intraclass variance of the pixels classified as black or white and to maximize the variance inter black and white classes. The second one (Fig. 3 , right) is based again on Otsu's method but applied on a modified histogram performed by the adjustment in the raw histogram of pixels with a grey level low (between 0 and 50) to the total range of grey intensity from 0 to 255. The Matlab program performs morphological operations on binary image in order to remove isolated pixels, this allows using Grey level 1 to individualize each LED (Fig. 3, left) while Grey Level 2 includes the red scattered light area. 
The variables extracted for each segmented image are: Illuminated area (number of pixels above level), Mean grey level (MGL) for the illuminated area (256 grey levels were considered) and Standard deviation (SD) of grey levels in the illuminated area $( \pm$ grey level).

Significant differences between treatments of ovoproducts were determined using variance analysis (one-way ANOVA, Statistica 6.1 StatSoft). Fisher's least significant differences test was used to determine the significant differences between group means $(\mathrm{p}<0.05)$.

\section{RESULTS AND DISCUSSION}

Table 1 shows ANOVA results for the three optical parameters extracted from raw image categorized by each individual LED. For following ovoproducts evolution at $9^{\circ} \mathrm{C}$ was considered as especially relevant the information corresponding to HTST product with four dates of sample analysis along storage at cold room. Based on Table 1 information it was decided to use the MGL as more important parameter for following $9^{\circ} \mathrm{C}$ evolution. While illuminated area seems to be most explicative parameter for address the ovoproducts behaviour at $2^{\circ} \mathrm{C}$.

\section{Experiment at storage temperature of $9^{\circ} \mathrm{C}$}

Fig. 4 shows the increase of the number of microorganism regarding storage time, with a fit to the sigmoid model of $\mathrm{r}^{2}=0.99$ for both types of ovoproducts. Also some optical parameter can be fitted $\left(\mathrm{r}^{2}{ }_{\mathrm{HTST}}=0.96\right)$ to such sigmoid behavior using the equation 1 , where $M G L$ is de mean grey level at $t$ time, $M G L_{\min }$ and $M G L_{\max }$ are the minimum and maximum values respectively of full grey level range registered in that test, and $a$ and $b$ are the adjusted parameters of model. The analysis of variance carried out shows that the MGL increases significantly with higher storage times (for MGL emitted by LED1 $\mathrm{F}_{\mathrm{TP}}=13.18$ and $\mathrm{F}_{\mathrm{HTST}}=26.69$ ).

$$
M G L(t)=M G L_{\min }+\frac{M G L_{\max }-M G L_{\min }}{1+e^{-(a+b t)}}
$$

Egg white liquefaction along storage time is one of the main product alterations described. The microorganisms' growth causes the proteins denaturalization, which are the $10 \%$ of egg white composition. Taking into account that the other $85 \%$ of egg white is water, that proteins' denaturalization would explain a decrease of product viscosity (Thapon 1994), lower optical density of the ovoproduct with not only significant higher values of red light intensity registered by the IRRB camera but also significant bigger illuminated areas by each LEDs (for parameter illuminated area by LED1 $\mathrm{F}_{\mathrm{TP}}=98.76$ and $\mathrm{F}_{\text {HTST }}=10.95$ ).

The correlation coefficients between the MGL optical parameter and microorganism growth, ranges from 0.9 to 0.98 for HTST and TP ovoproducts respectively. Fig. 5 shows an estimation of biomass concentration based on optical properties of samples. Taking into account only one optical parameter corresponding to a single LED (LED1) it is possible to develop very simple predictive models defined by equation 2 for HTST product and equation 3 for TP product, where $x$ corresponds to MGL and $y$ refers to $\log (\mathrm{UFC} / \mathrm{ml})$. 


$$
\begin{aligned}
& \frac{y-1.76}{7.36-y}=\left(\frac{0.11(x-126.28)}{137-x}\right)^{0.9} \\
& \frac{y-3.6}{8.57-y}=\left(\frac{3.13(x-127.27)}{133.16-x}\right)^{0.43}
\end{aligned}
$$

\section{Experiment at storage temperature of $2^{\circ} \mathrm{C}$}

Lorient and Matringe (1994) described that storage of egg product at low temperature induces viscosity increases due to gelation process of proteins. This effect could explain in Fig. 6 the decrease in the optical parameters studied especially for the values of illuminated area by LEDs at the end of a long storage in cold room at $2^{\circ} \mathrm{C}$. Any way, the lack of optical tests between the end of lag phase and the end of exponential phase in growth microorganism curve impedes modeling the optical parameters with respect the microorganism growth, and thus it is necessary to design and carry out a new experiment to study this case.

On the other hand Fig.7 shows how the HTST ovoproduct, made under more restrictive pasteurization conditions, maintains along cold storage at $2^{\circ} \mathrm{C}$ approximately 100 times less $\mathrm{UFC} / \mathrm{ml}$ than samples corresponding to TP product. The significantly lower value registered for the parameter "illuminated area" shown in Fig. 6 for HTST product at $2^{\circ} \mathrm{C}$, allows far a clear differentiation between both types of ovoproducts $\left(\mathrm{F}_{\mathrm{LED} 1}=254.4\right)$. Along cold storage at $2^{\circ} \mathrm{C}$ the optical parameter MGL tends to be bigger, while "illuminated area" tends to be smaller for HTST product than TP products. This tendency is also found in cold storage at $9^{\circ} \mathrm{C}$. It seems that the lower microorganism concentration decreases the turbidity of HTST samples being the red LED scattering lower.

\section{CONCLUSIONS}

In egg white samples storage in cold rooms at $9^{\circ} \mathrm{C}$ is possible to fit a sigmoid model to the samples' evolution along storage time using the optical parameter MGL, extracted from segmented images of red light emitted by LEDs passing trough the ovoproduct sample. The high correlation found between the sigmoid evolution of MGL corresponding to one LED of the optical device and the microbial growth, allows to build predictive models. Taking into account only one optical parameter corresponding to a single LED (LED1) it is possible to develop very simple predictive models.

\section{ACKNOWLEDGMENTS}

The funding of this work has been covered by TAGRALIA-CM research group, Polytechnic University of Madrid and CAL 03-018-C3-1.

\section{Literature Cited}

Cairé, M.E., Vignolo, G.M. and Garro, O.A. 2007. Selection of a Primary Model for to Describe the Growth Curve of Lactic Acid Bacteria and Brochothrix thermosphacta on Cooked Meat Emulsions. Información Tecnológica 18, no 3: 23-30.

Castillo, M., J. A. Lucey, and F. A Payne. 2006. The effect of temperature and inoculum concentration on rheological and light scatter properties of milk coagulated by a combination of bacterial fermentation and chymosin. Cottage cheese-type gels. 
International Dairy Journal, no. 16.

Coimbra, Jane S. R., Ana L. Gabas, Luis A. Minim, Edwin E. Garcia Rojas, Vania R. N. Telis, and Javier Telis-Romero. 2006. Density, heat capacity and thermal conductivity of liquid egg products. Journal of Food Engineering 74, no. 2.

Guilmineau, F., and U. Kulozik. 2007. Influence of a thermal treatment on the functionality of hens egg yolk in mayonnaise. Journal of Food Engineering, no. 78.

Hou, H., R. K. Singh, P. M. Muriana, and W. J. Stadelma. 1996. Pasteurization of intact shell eggs. Food Microbiology, no. 13.

Lorient, D., and E. Matringe. 1994. Proprietés Fonctionelles. L'oeuf et les ovoproduits. J. L. Thapon, and C. M. BourgeoisParis: Technique et Documentation.

Mańas, P., R. Pag!an, I. Alvarez, and S. Condón. 2003. Survival of Salmonella senftenberg $775 \mathrm{~W}$ to current liquid whole egg pasteurization treatments. Food Microbiology, no. 20.

Thapon, J. L. 1994. Évolution de l'oeuf au cours de la conservation de l'oeuf. L'oeuf et les ovoproduits. J. L. Thapon, and C. M. BourgeoisParis: Technique et Documentation.

\section{Tables}

Table 1. Effect of cold storage time on evolution of the three optical variables extracted from each LED, through Fisher $F$ (significant for $\mathrm{p}<0.05$ ) of one-way ANOVA categorized by ovoproduct type and temperature at cold room.

\begin{tabular}{|c|c|c|c|c|}
\hline & $\begin{array}{r}\text { HTST at } 2^{\circ} \mathrm{C} \\
(\mathrm{n}=27)\end{array}$ & $\begin{array}{r}\text { HTST at } 9^{\circ} \mathrm{C} \\
(n=36)\end{array}$ & $\begin{array}{r}\text { TP at } 2^{\circ} \mathrm{C} \\
(n=27)\end{array}$ & $\begin{array}{r}\mathrm{TP} \text { at } 9^{\circ} \mathrm{C} \\
(\mathrm{n}=27)\end{array}$ \\
\hline Area LED1 & 1268.10 & 10.96 & 144.51 & 98.76 \\
\hline Area LED2 & 1041.79 & 15.38 & 255.50 & 67.02 \\
\hline Area LED3 & 1210.17 & 4.67 & 136.75 & 67.85 \\
\hline MGL LED1 & 49.85 & 26.69 & 31.43 & 13.18 \\
\hline MGL LED2 & 13.93 & 4.34 & 40.16 & 16.27 \\
\hline MGL LED3 & 0.56 & 16.60 & 39.66 & 33.19 \\
\hline SD LED1 & 47.05 & 7.90 & 15.22 & 7.68 \\
\hline SD LED2 & 131.97 & 14.69 & 37.15 & 15.07 \\
\hline SD LED3 & 46.77 & 15.71 & 64.78 & 38.20 \\
\hline
\end{tabular}

\section{Figures}




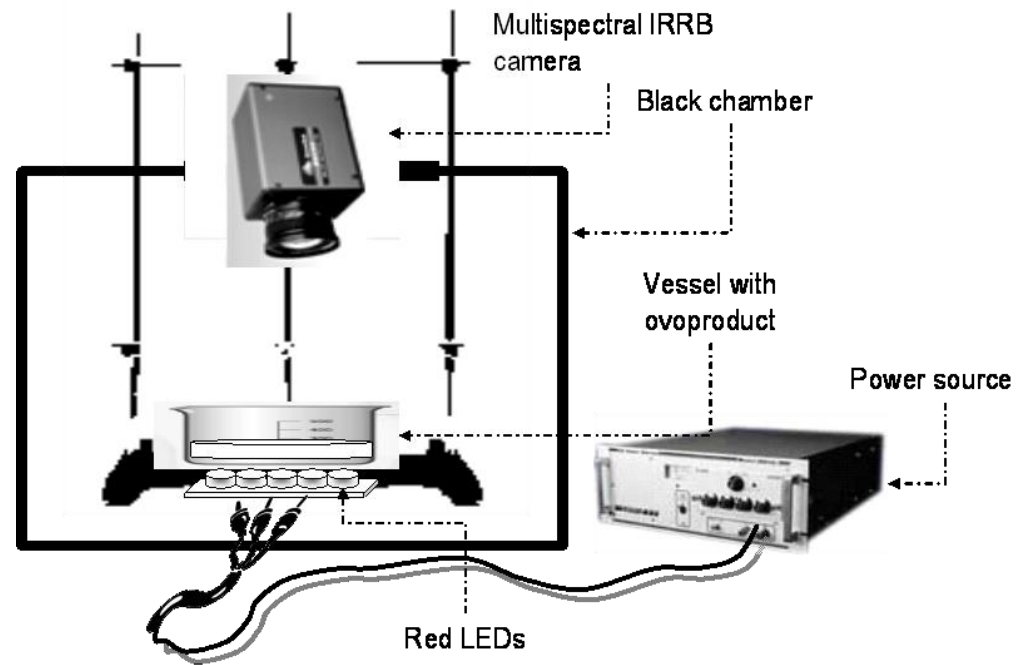

Fig. 1. Scheme of optical test procedure.

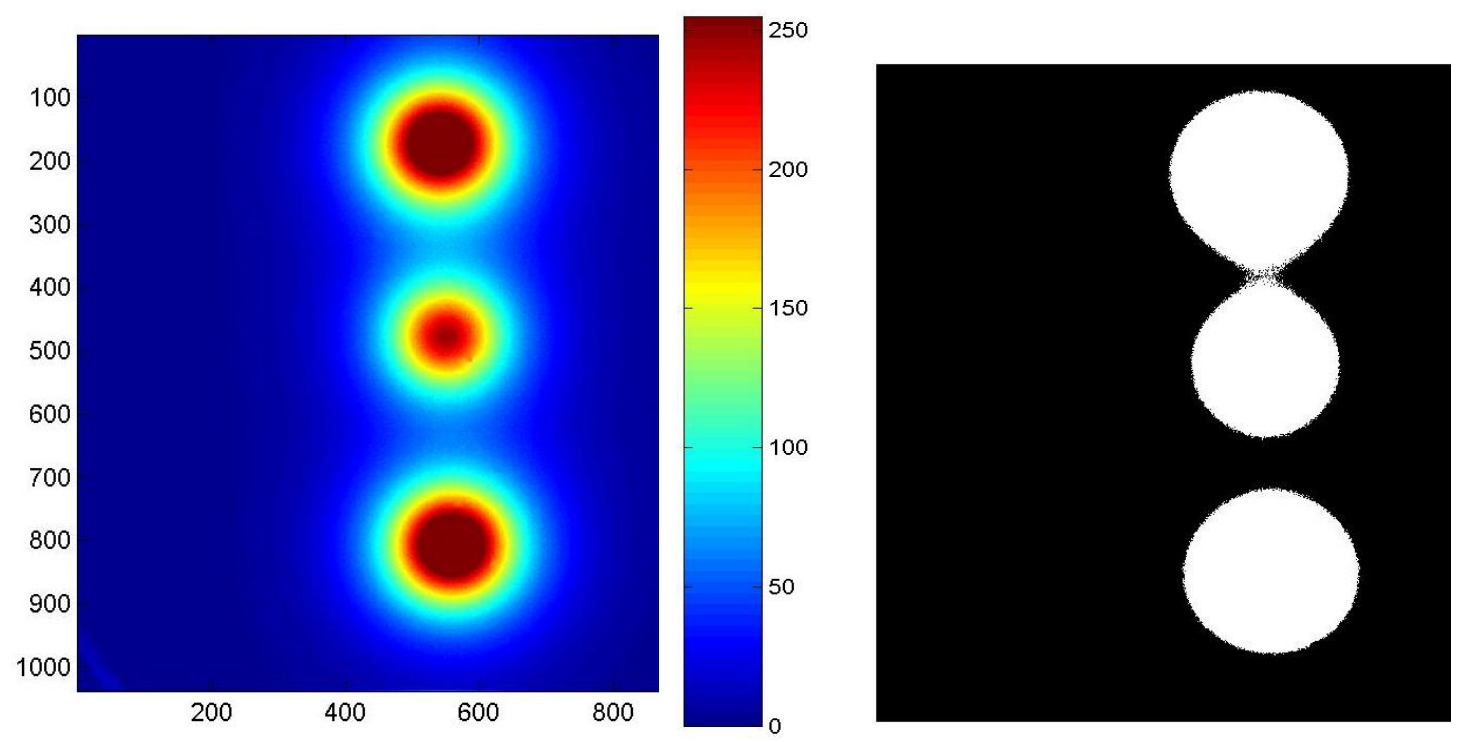


Fig. 2. On the left, raw auto scaled image corresponding to red channel of 3CCD IRRB camera, on the right the corresponding image after apply segmentation level 1.
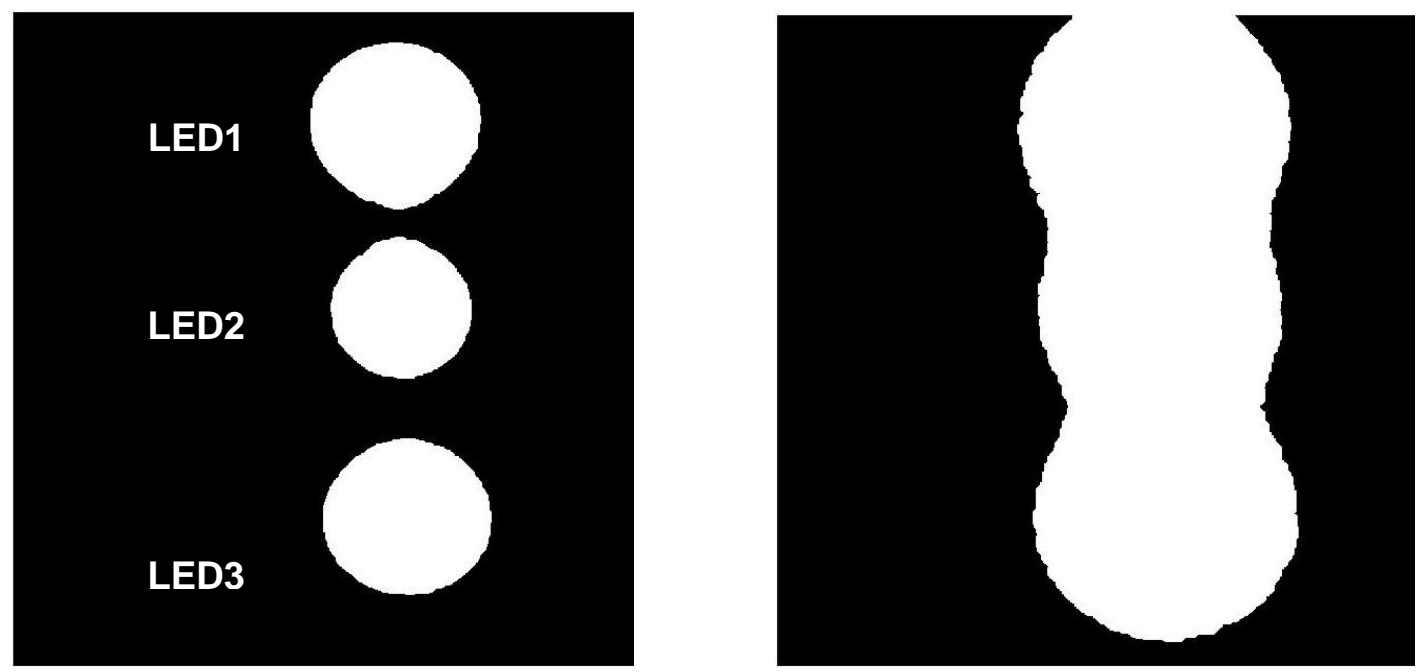

Fig. 3. On the left, individualized LEDs subtracting pixels placed in the middle areas and on the right global area illuminated by three LEDs after apply segmentation level 2 on raw image shown in Fig.2. 

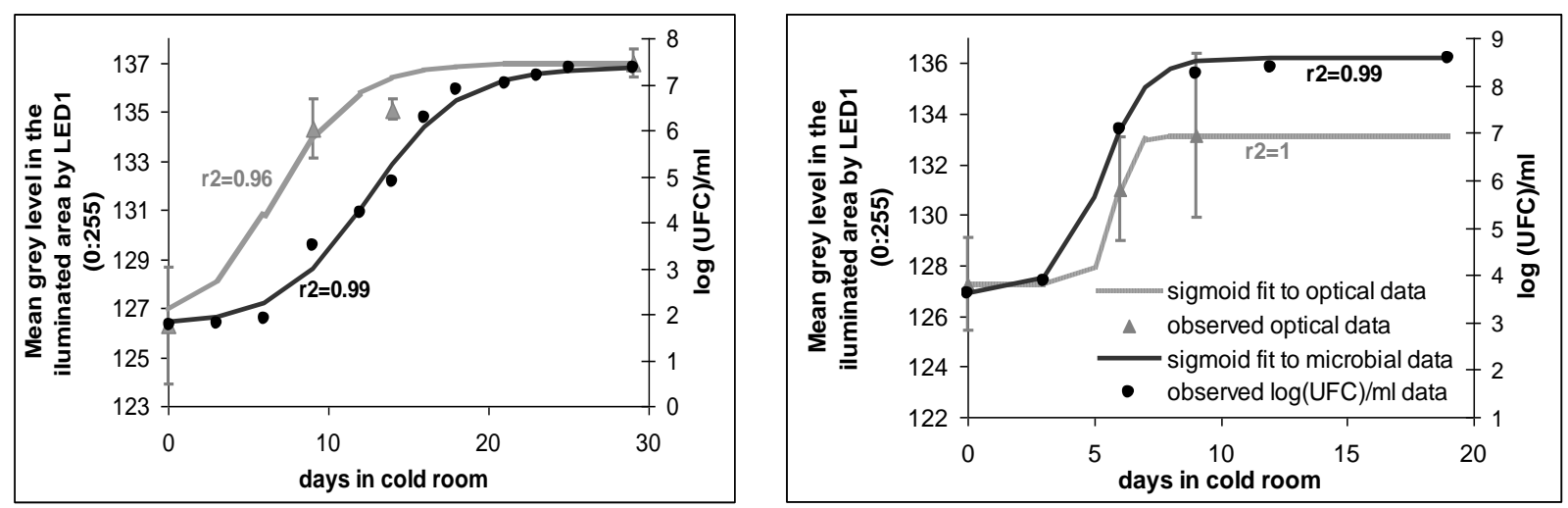

Fig. 4. Sigmoid increase of optical parameters (mean grey level) and micro organism number $(\log (\mathrm{UFC} / \mathrm{ml}))$ along days in cold room at $9^{\circ} \mathrm{C}$ for HTST product (on the left) and TP product (on the right).
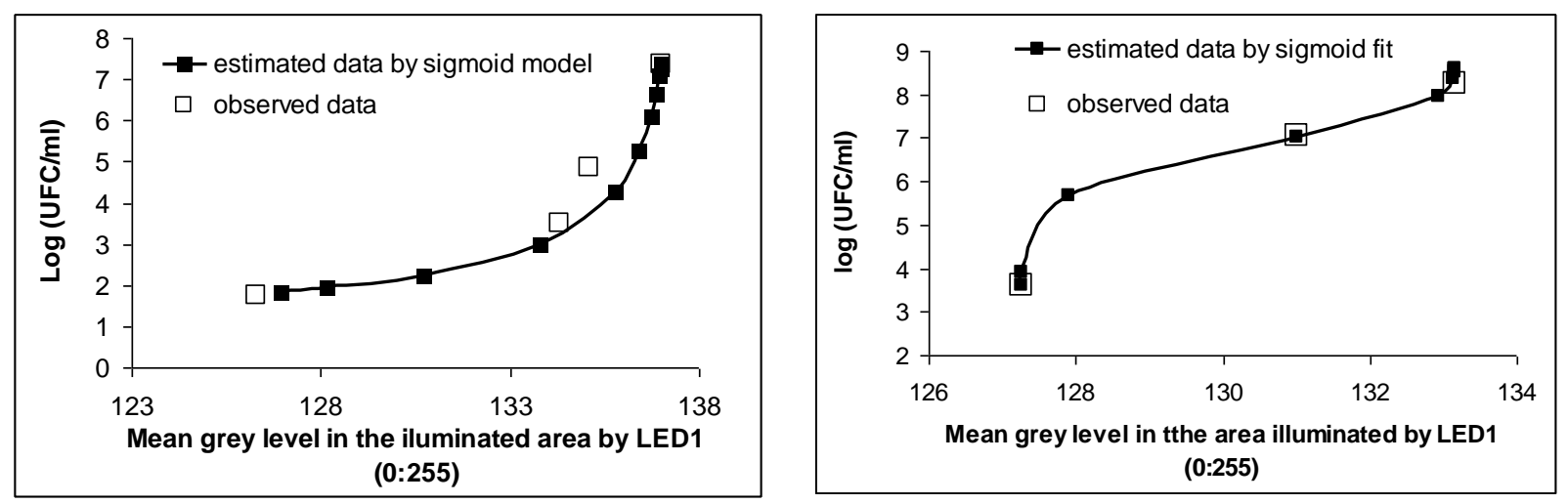

Fig. 5. Fit models to predict number of micro organism $(\log (\mathrm{UFC} / \mathrm{ml}))$ from optical parameter observed (mean grey level). On the left HTST product at $9^{\circ} \mathrm{C}$, on the right TP product at $9^{\circ} \mathrm{C}$.

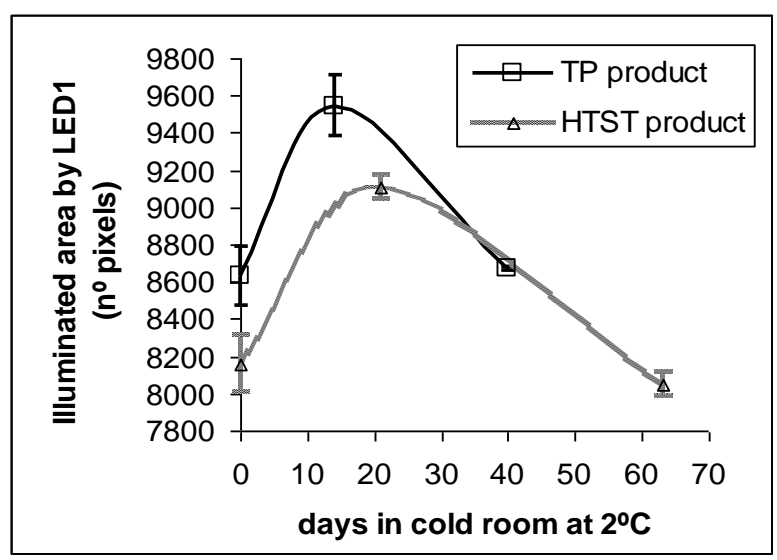

Fig. 6. Evolution of the optical parameter "illuminated area" along days in cold room at $2^{\circ} \mathrm{C}$.

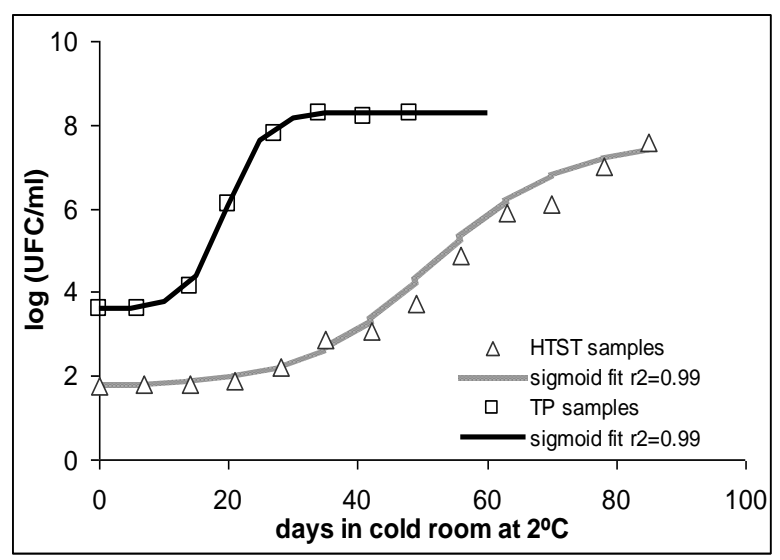

Fig.7. Microorganism growth curve corresponding to TP and HTST product along storage time at $2^{\circ} \mathrm{C}$. 